Article

\title{
Real-Time Detection of Long Lived Near Infrared luminescence from Colourless Cubic Zirconia by Time-Gated Imaging
}

\author{
Peter M. P. Lanigan ${ }^{1}$ * , Colin D. McGuinness ${ }^{1}$, Mark Rendle ${ }^{1}$, Peter A. Aked ${ }^{1}$, \\ Christopher G. Bearcroft ${ }^{1}$, Daniel C. Jones ${ }^{2} \mathbb{D}$ and Simon C. Lawson ${ }^{1}$ \\ 1 De Beers Group Technology UK, Belmont Road, Maidenhead, Berkshire SL6 6JW, UK; \\ Colin.McGuinness@debeersgroup.com (C.D.M.); mark.rendle@debeersgroup.com (M.R.); \\ Peter.Aked@debeersgroup.com (P.A.A.); Christopher.Bearcroft@debeersgroup.com (C.G.B.); \\ Simon.Lawson@debeersgroup.com (S.C.L.) \\ 2 Photonics Group, Department of Physics, Imperial College London, South Kensington Campus, \\ London SW7 2AZ, UK; d.jones17@imperial.ac.uk \\ * Correspondence: peter.lanigan@debeersgroup.com
}

Received: 1 September 2020; Accepted: 2 October 2020; Published: 8 October 2020

\begin{abstract}
Here, we report a long-lived ms time scale decay luminescing in the near infrared $>800 \mathrm{~nm}$ present in productions of 'white' colourless, facetted yttrium stabilized cubic zirconia and observed using time-gated imaging. The spectrum of the strong luminescing feature also has characteristics of Neodymium $\left(\mathrm{Nd}^{3+}\right)$ and has a multiexponential decay behaviour. Real-time detection of cubic zirconia mounted in diamond jewellery containing very small stones $(\leq 0.01 \mathrm{ct})$ is made possible, where observation by loupe is more challenging or other conventional techniques impractical and or slow to implement. The near infrared observed can be excited using a low-cost and eye/skin safe-visible green LED light source and the time-gated imaging of the luminescence using a machine vision monochrome camera. The use of near infrared, time-gated detection in combination with other verification instruments increases the robustness of screening diamond parcels. Therefore, it is recommended that any stone exhibiting strong delayed luminescence in the near infrared be treated with caution, as this is not a typical feature found in this precious gemstone. In this case, the instrument developed was expanded to incorporate a white LED illumination ring as a viewfinder, in order to aid the inspection of loose and mounted configurations.
\end{abstract}

Keywords: cubic zirconia; simulants; diamond substitutes; CZ; time-gated; real-time; near infrared; lifetime imaging; nitrogen vacancy

\section{Introduction}

In contrast to synthetic diamonds, diamond substitutes or 'simulants' are other materials that resemble diamonds by eye, and may exhibit similar properties, e.g., high refractive index and hardness and a "good colour" (near-colourless to colourless). Some simulants occur in nature, while others are man-made. Common simulants include cubic zirconia $\left(\mathrm{ZrO}_{2}\right)$, zircon $\left(\mathrm{ZrSiO}_{4}\right)$, strontium titanate $\left(\mathrm{SrTiO}_{3}\right)$, yttrium aluminium garnet $\left(\mathrm{Y}_{3} \mathrm{Al}_{5} \mathrm{O}_{12}\right)$ (known as $\left.\mathrm{YAG}\right)$, synthetic moissanite $(\mathrm{SiC})$, gadolinium gallium garnet $\left(\mathrm{Gd}_{3} \mathrm{Ga}_{5} \mathrm{O}_{12}\right.$, or GGG), synthetic rutile $\left(\mathrm{TiO}_{2}\right)$, glass $\left(\mathrm{SiO}_{2}\right)$, synthetic spinel $\left(\mathrm{MgAl}_{2} \mathrm{O}_{4}\right)$ and synthetic sapphire $\left(\alpha-\mathrm{Al}_{2} \mathrm{O}_{3}\right)$. Unlike diamonds, simulants do not attract high values at retail, making it clearly desirable from a commercial perspective to provide a reliable means of identifying and sorting them from natural diamonds. The separation of common simulants from diamonds can be very straightforward and there are effective traditional tools and analytical procedures known for some decades to sort simulants from diamonds [1-6]. More recently, commercial instruments have become 
available to automatically sort cubic zirconia from large batches of small diamonds [7-9]. As reported in the press [10], natural diamond verification for very small diamonds, especially in set jewellery is not obvious, however, recent advances in new measurement technologies harnessing the power of time-gated imaging have made this a much less onerous task [11-14].

\section{Cubic Zirconia (CZ)}

$\mathrm{CZ}$, the synthetic crystal form of $\mathrm{ZrO}_{2}$, is an excellent simulant because of its high brilliance, hardness, chemical inertness, low dispersion, isotropic crystal structure, high transparency and flawlessness and its high band gap, hence near-colourless appearance. The pioneering work of several groups to develop the skull melting process [15] has established CZ as a very low-cost synthetic stone [16,17], retailing wholesale for as little as USD 2 for an equivalent-sized 1 carat round brilliant diamond. Thought initially to be an issue for diamond commercially, early studies in the 1980s showed that retail of CZ and other simulants were less than $1 \%$ of total diamond sales by value [1]. Thankfully, to the diamantaire's trained eye, it is possible to discern differences between $\mathrm{CZ}$ and diamond. In the trade, over the years, several instances of $\mathrm{CZ}$ and other substitutes have been identified trying to pass for the real thing, for example, in imitation rough $[18,19]$ and polished diamond parcels [20]. Well established verification methodologies include specific gravity, optical isotropy, thermal conductivity, wetting contact-angle, reflectivity, refractometry, UV-Vis-IR absorption, UV luminescence and of course Raman spectroscopy. However, these methods have their drawbacks, in that they usually measure a stone in isolation and become more difficult to employ when many stones are screened simultaneously in situ or require expensive, sophisticated-instrumentation and analysis. Moreover, it becomes increasingly difficult and time consuming for the diamantaire to discriminate $\mathrm{CZ}$ from diamond in large parcels and mounted jewellery when stones are very small $\left(<0.01 \mathrm{ct}\right.$, where $\left.1 \mathrm{ct}=2 \times 10^{-4} \mathrm{~kg}\right)$.

In the skull melting process, monoclinic powdered $\mathrm{ZrO}_{2}$ is heated at high temperatures to transition it to tetragonal form at $1100{ }^{\circ} \mathrm{C}$, and finally to the cubic structure of $\mathrm{CZ}$ at $>2000^{\circ} \mathrm{C}$. Unfortunately, if left to cool on its own, the above monoclinic-tetragonal-cubic transition sequence is reversible. To overcome this problem and block the reversibility of the melt, manufacturers add stabilisers, including $\mathrm{CaO}$, $\mathrm{MgO}$ and $\mathrm{Y}_{2} \mathrm{O}_{3}$ (yttrium $\left[\mathrm{Y}^{3+}\right]$ oxide). For colourless $\mathrm{CZ}, \mathrm{Y}_{2} \mathrm{O}_{3}$ is used most and added in the range 1-10 wt.\% [17], in what is called yttrium-stabilised zirconia (YSZ) [21]. Furthermore, often lanthanide ions such as praseodymium $\left(\mathrm{Pr}^{3+}\right)$ and neodymium $\left(\mathrm{Nd}^{3+}\right)$ are added to enhance or change their colour [1]. The latter ion is known to have a strong absorption in the yellow-green region of the spectrum thus producing purple colour in larger stones [22], has a strong near-infrared emission [23,24], and used as a dopant in YSZ [25] and YAG [26] laser crystals. Figure 1 shows several near-infrared emission spectra from common simulants, together with an example of a CZ synthetic stone produced with this infrared feature. Referring to Figure 1, it is believed that trace amounts of $\mathrm{Nd}^{3+}$ and other lanthanides in colourless YSZ generated the near-infrared luminescence spectroscopically measured and rapidly imaged in our system. 


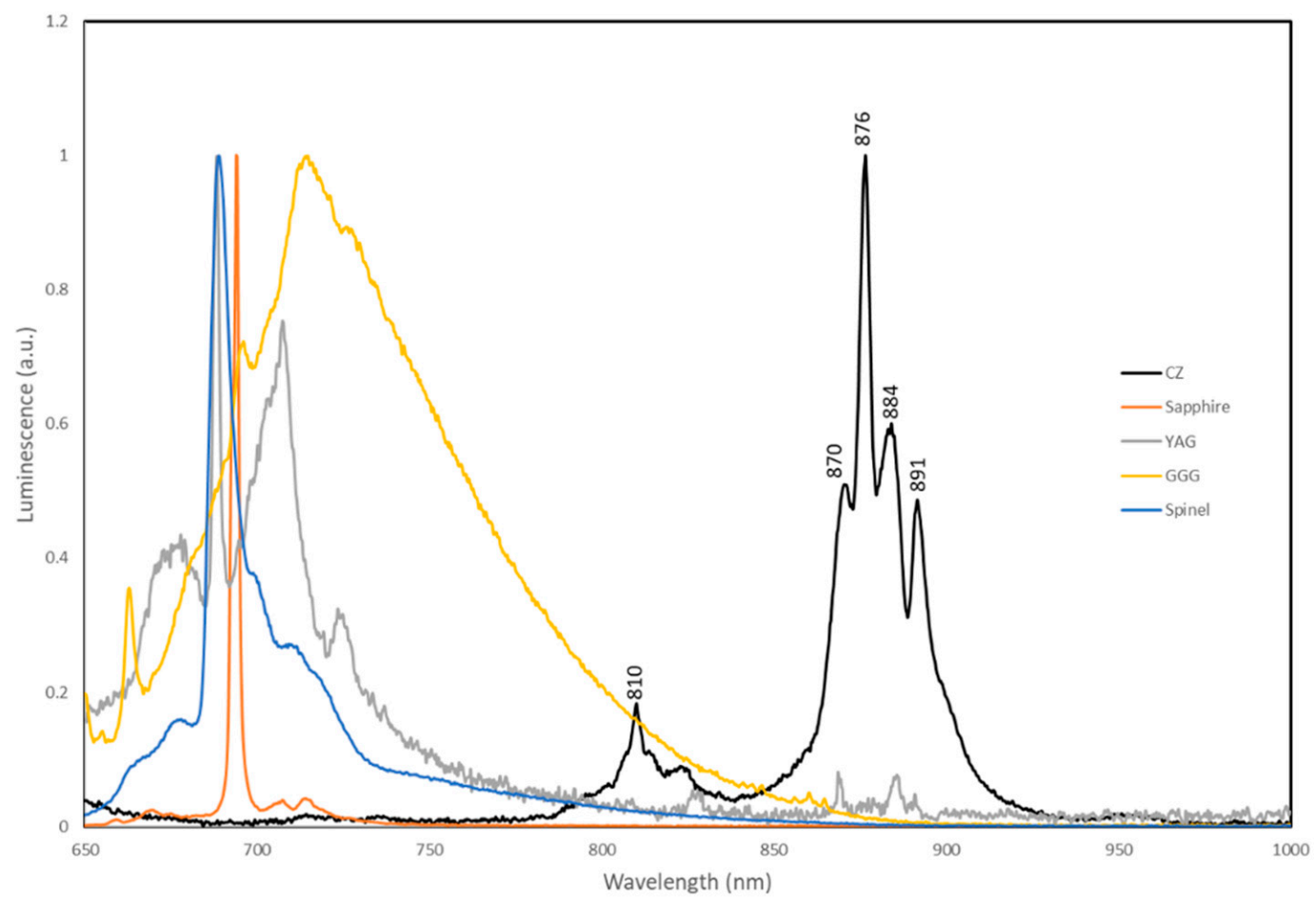

Figure 1. Near-infrared delayed luminescence spectra of common simulants measured on Horiba iHR-320 spectrometer, excitation at $550 \mathrm{~nm}$ (see Section Materials and Methods).

\section{Materials and Methods}

Over 1000 commercially available colourless CZ stones varying in size from $1 \mathrm{~mm}$ to $5 \mathrm{~mm}$ were tested from several manufacturers: Swarovski (Wattens, Austria), Pandora (Copenhagen, Denmark), Messi Gems (Wuzhou, China), Ceres Crystal US (New York, US) and Rough Synthetic Stones Co., Ltd (Bangkok, Thailand).

Spectral data were collected by an Andor iStar DH320T-18U-E3 intensified CCD camera via a Horiba iHR-320 spectrometer (Horiba, Kyoto, Japan). The broad band excitation source used was a Hamamatsu Photonics L7685 xenon flash lamp spectrally filtered to $550 \pm 25 \mathrm{~nm}$ output with temporal pulse width of $\sim 3 \mu$ s at full width half maximum. Synchronisation with the flash lamp and camera was supplied by two externally generated TTL signals, with the lamp signal offset by $11 \mu$ sith respect to the camera signal to account for the difference in latency between the two devices. Delayed luminescence was recorded with a $1 \mathrm{~s}$ exposure time and accumulated for 40 averages resulting in a $40 \mathrm{~s}$ total acquisition time. Photon counting time-resolved decay data was collected by a Horiba Jobin Yvon IBH TBX-04 thermoelectrically cooled photomultiplier module via a Horiba iHR-320 spectrometer (Horiba, Kyoto, Japan) with excitation as above. Detector and flash lamp are triggered simultaneously with channels recording excitation pulses rejected and strobe operation at $30 \mathrm{~Hz}$.

Sub-millisecond time-gated imaging of near-infrared luminescence was carried out using a Teledyne Dalsa Genie Nano M2050 monochrome area scan CMOS camera (Teledyne Technologies, Thousand Oaks, CA, USA), with IR-cut filter replaced with a glass window. Camera and green LEDs (LUMILED Luxeon Z colour line LXZ1-PM01 520-540 nm) were synchronised using the camera's internal trigger, with the green LEDs offset pulse delay and duration set to $2.1 \mathrm{~ms}$ and $2 \mathrm{~ms}$ respectively, with camera exposure time set to 2 ms. Camera and white LEDs (LUMILED Luxeon Z ES LXZ2-6570) were synchronised as above, using the camera's second internal trigger line with $0 \mathrm{~ms}$ offset pulse delay; pulse duration and camera acquisition time set to $10 \mathrm{~ms}$. 
Monochrome 8-bit images of $1296 \times 1296$ pixels were captured in real-time then transferred to a PC. All software was written in C\# referencing the Teledyne Sapera LT SDK libraries, with a GUI built on Windows Presentation Foundation (WPF), to configure capture conditions and display images.

The optics layout for image capture of near-infrared luminescence from CZ comprised of mainly off the shelf optical components and mechanics and is shown in Figure 2; the total cost is approximately 1000 Euros in parts. The imaging system allowed for sequential white-light and near-infrared luminescence imaging of $\mathrm{CZ}$ and natural diamond with a $25 \mathrm{~mm}$ diameter field of view. Variable aperture setting on the camera lens allowed the manipulation of depth of field for jewellery testing. The resolution of the system was tested at F\#1.4 using a United States Air Force (USAF) resolution chart and Group 4 elements (16-28 cyc/mm) were visible throughout taking advantage of the aperture stop position to control astigmatism, leaving coma and field curvature aberrations to dominate towards the field edges. A combined custom green and white LED ring illuminator was employed for exciting near-infrared luminescence and for pseudo dark-field imaging respectively, the latter serving as a viewfinder to conveniently locate stones in the field of view. The use of white LEDs here was improvised, and in fact, an infrared LED ring illuminator would have been optimum to provide transmission through the long pass filter. The ring illuminator comprised of an inner ring of $34 \mathrm{~mm}$ diameter with 14 green LEDs, driven in series at approx. $1 \mathrm{~A}$ and an outer ring of $75 \mathrm{~mm}$ diameter with 24 white LEDs, in four parallel strings of 6 LEDs, each driven at approx. $300 \mathrm{~mA}$, resulting in $1200 \mathrm{~mA}$ total drive current; in both cases, LEDs were equally spaced around their respective circumferences and positioned along the optical axis approximately $35 \mathrm{~mm}$ from the sample tray.

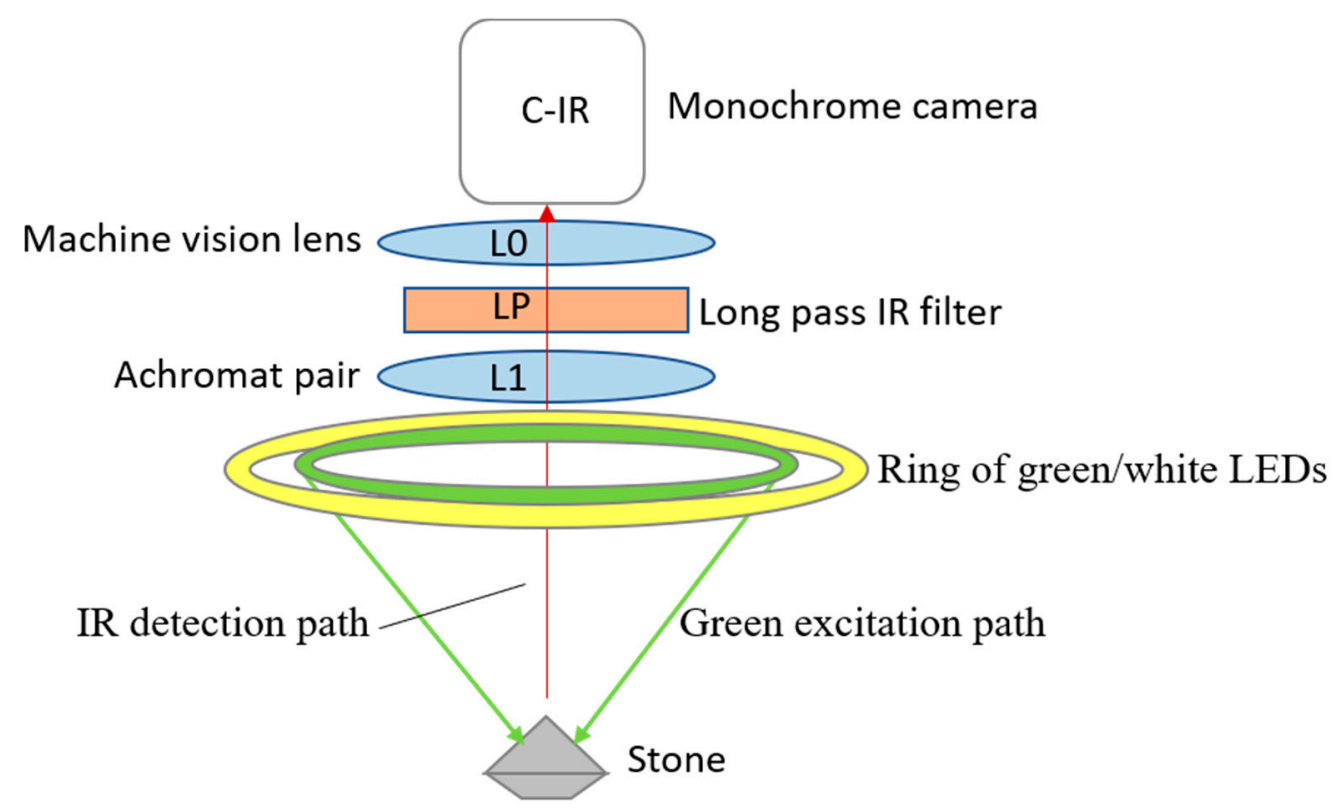

Figure 2. Schematic of $\times 0.25$ magnification imaging system for capture of near IR luminescence from Cubic Zirconia (CZ). L0 = F\#1.4 25mm lens (HF25HA-1S Fujinon, Fujifilm, Tokyo, Japan), L1 = 2 mm $\times 200 \mathrm{~mm}$ achromats (200DQ25, Comar Optics Ltd, Cambridge, UK), LP $=808 \mathrm{~nm}$ cut-off infrared long pass filter (BLP01-808R-25, Semrock, IDEX Health \& Science LLC, New York, NY, USA), C-IR = monochrome Teledyne Dalsa Genie Nano M2050 camera with glass filter.

\section{Results}

\subsection{Near Infrared Time-Resolved Decay Measurements}

To determine optimum capture conditions for CZ near-infrared luminescence, we captured timeresolved decay data with spectral emission centred at $876 \mathrm{~nm}$. A typical example of this luminescence decay for $\mathrm{CZ}$, which is built up as a histogram of photon arrival times after excitation from a narrow 
pulse is shown in Figure 3 (see materials and methods for details). The decay could be adequately fit to a decay model of three exponentials with lifetimes $(\tau)$ of $\tau_{1}=60 \mu \mathrm{s}, \tau_{2}=600 \mu \mathrm{s}$ and $\tau_{3}=10 \mathrm{~ms}$ respectively and weighted average lifetime $\tau_{\mathrm{av}}=950 \mu$ s with reduced $\mathrm{chi}^{2}=1.02$. The data gave an indication that most of the luminescence from $\mathrm{CZ}(>70 \%)$ decayed within $2 \mathrm{~ms}$ after excitation, thus setting the acquisition time for our imaging system.

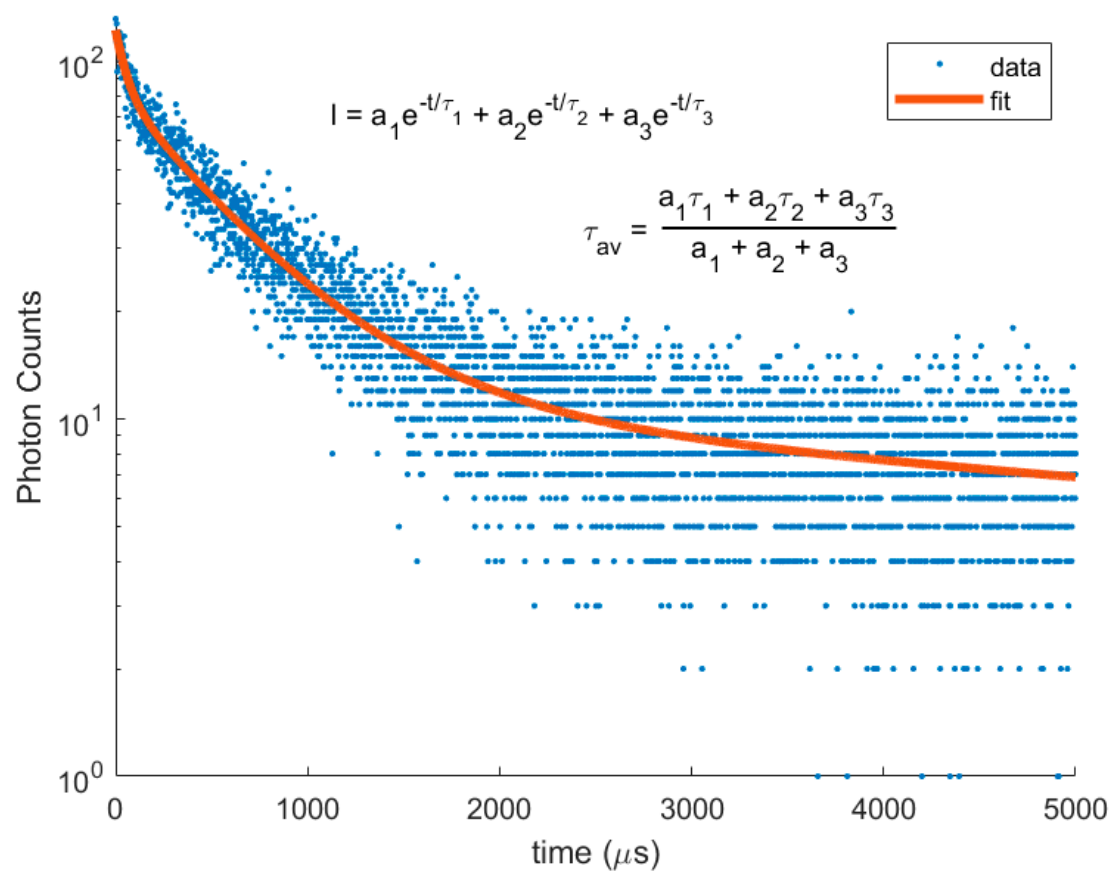

Figure 3. Time-resolved decay data (blue) and 3-exponential fit (red) acquired at $876 \mathrm{~nm}$ from CZ using $550 \mathrm{~nm}$ excitation filtered xenon-arc source.

\subsection{Near Infrared Time-Gated Imaging of Loose and Mounted CZ and Natural Diamonds}

The start time for image capture, on the other hand, can be determined for example, by observing the typical emission characteristics of common colour centres in natural diamond, e.g., Nitrogen Vacancy in the negative charge state $\left(\mathrm{NV}^{-}\right)$. $\mathrm{NV}^{-}$has a Zero Phonon Line at $637 \mathrm{~nm}$ and 'fluorescence' emission that extends into the near-infrared region of the spectrum overlapping with that of $\mathrm{CZ}$. As the definition of fluorescence here is the signal produced concurrently with the excitation source, a lower limit on the exposure delay for $\mathrm{CZ}$ can be set after the LED pulse duration has ended. The combination of exposure delay and exposure time can, therefore, be optimised for $\mathrm{CZ}$, with $\mathrm{NV}^{-}$signal conveniently filtered out in time as well as spectrally. Example real time infrared images of cut CZ with the delay before the imaging of $2.1 \mathrm{~ms}$ used to exclude near-infrared emission from diamonds and the image was captured over the next $2 \mathrm{~ms}$, to efficiently capture the emission from the CZ stones, shown in Figure 4 for three different sizes.

Real time measurements were also made on a diamond encrusted band adorned with $\sim 0.01 \mathrm{ct}$ diamonds and two CZ synthetic stones. In this situation, under normal white-light imaging, it is more challenging to pick out CZ from neighbouring diamonds, as shown in Figure 5a,d,g,j.

However, with the infrared luminescence channel, it is more straightforward to ascertain that the band contains $C Z$ as shown in Figure $5 b, e, h, k$ and for greater clarity in yellow false colour overlays to pinpoint its location within the piece, as shown in Figure $5 c, f, i, 1$. A comparison of results of the same ring obtained with a typical gemmological LWUV (366 nm) lamp is shown in Figure 6, together with a natural stone containing $\mathrm{NV}^{-}$showing strong characteristic orange luminescence and loose CZ showing weak yellow luminescence. This shows the challenge of finding CZ in this band and the potential overlap emission from natural diamonds with emission from colour centres, such as $\mathrm{NV}^{-}$, and thus require good spectral and temporal separation of these signals with the signature 
from CZ. In addition SWUV $(<240 \mathrm{~nm})$ illumination as shown in Figure 6e,f produces week blue-grey luminescence, which is difficult to interpret against the background of both inert and strong-blue luminescence originating from the natural diamonds.
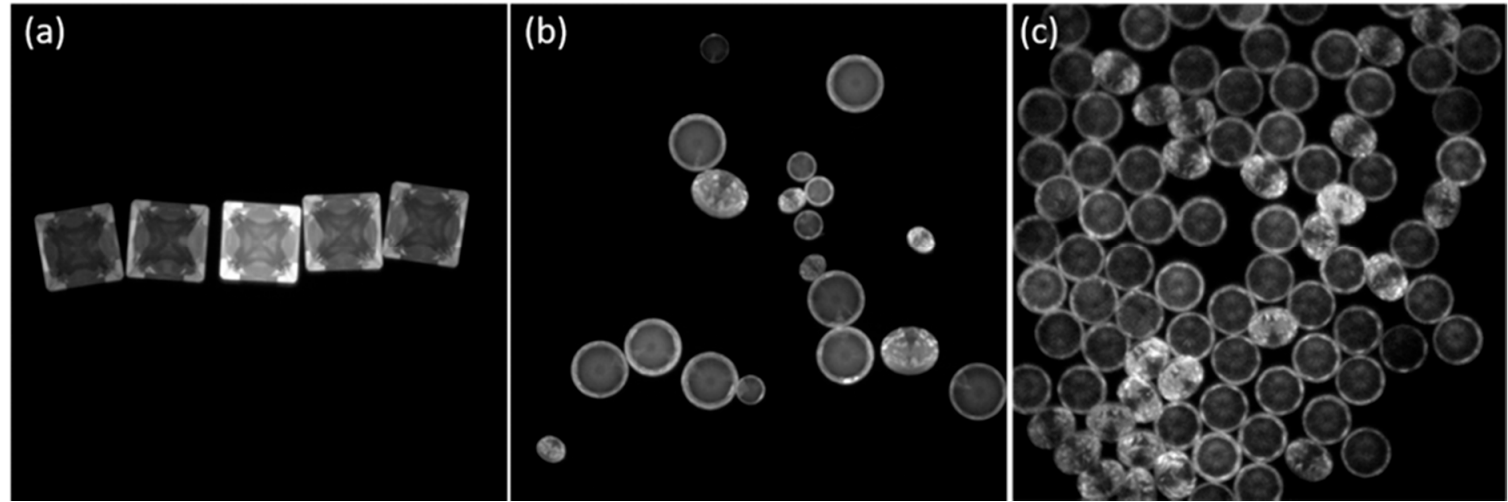

Figure 4. Here; $17 \mathrm{~mm} \times 17 \mathrm{~mm}$ field of view, example images of near-infrared emission from $\mathrm{CZ}$ from different manufacturers, (a) Swarovski $2.75 \mathrm{~mm}$ Princess cut, (b) Ceres Crystal US: $1 \mathrm{~mm}$ and $2 \mathrm{~mm}$ Round cut, (c) Messi Gems 1.7 mm Round cut.
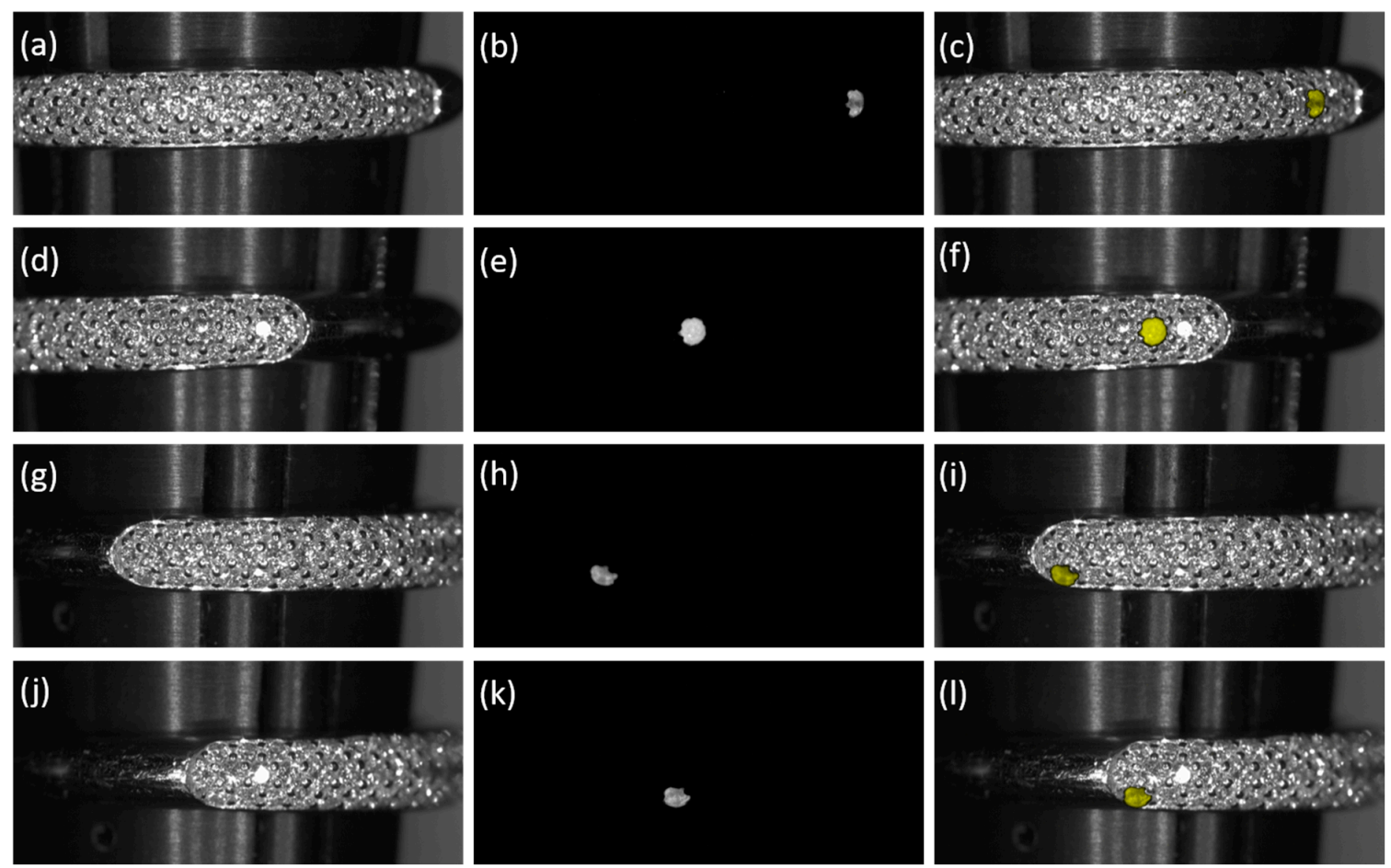

Figure 5. Images of diamond ring jewellery containing two $C Z$ synthetic stones hidden in diamond encrusted band. Left to right: the jewellery piece was in a static position and images acquired in white-light at F\#4 (a,d,g,j), near-infrared luminescence with green LED excitation at F\#1.4 (b,e,h,k) and resulting yellow false colour overlay $(\mathbf{c}, \mathbf{f}, \mathbf{i}, \mathbf{l})$. Rows beginning (a) and (d) first CZ stone imaged at two viewpoints as band rotated. Rows beginning $(\mathbf{g})$ and $(\mathbf{j})$ second $\mathrm{CZ}$ stone imaged at two viewpoints as band rotated.

Furthermore, real time image capture with $2 \mathrm{~ms}$ exposure time is shown in Figure 7 and strong colour centre emission $\mathrm{NV}^{-}$and any residual excitation bleed through is effectively gated-out by the instrument leaving just the infrared emission from $\mathrm{CZ}$ after $2.1 \mathrm{~ms}$ exposure delay. 


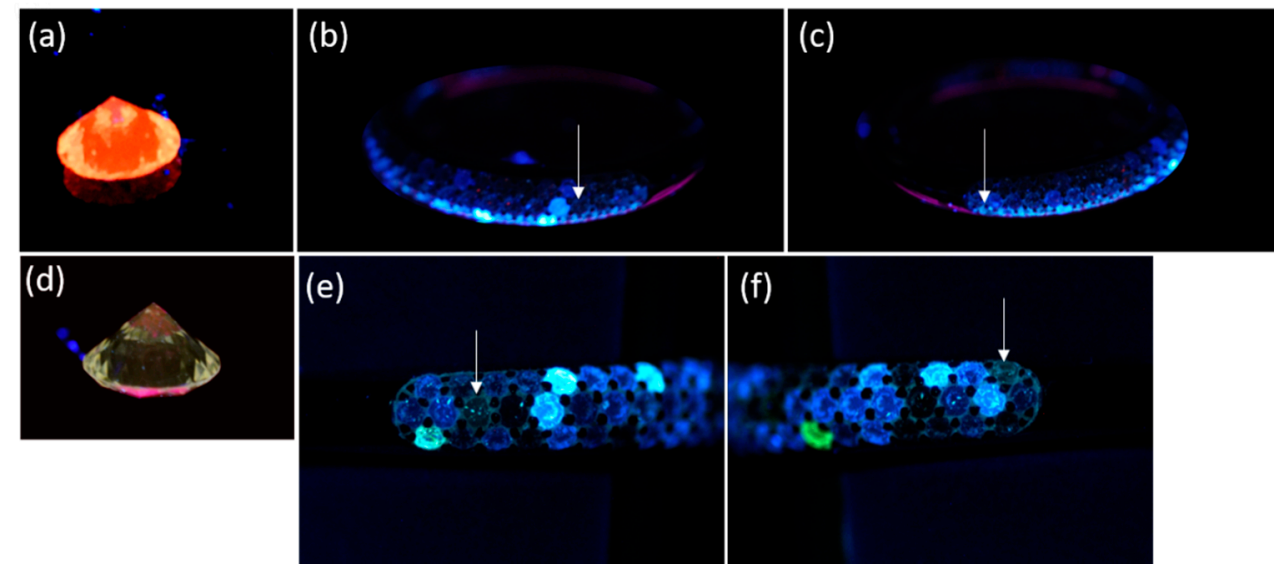

Figure 6. Photograph of (a) orange fluorescing natural diamond with $\mathrm{NV}^{-},(\mathbf{b}, \mathbf{c})$ ring as in Figure 5, $\mathrm{CZ}$ stones indicated by arrows excited by LWUV $(366 \mathrm{~nm})$ gemmological lamp showing no observable luminescence, (d) loose $\sim 5 \mathrm{~mm} \mathrm{CZ}$ stone showing weak yellow fluorescence also excited by LWUV, $(\mathbf{e}, \mathbf{f})$ images of same ring, CZ stones indicated by arrows, excited by SWUV $(<240 \mathrm{~nm})$, showing weak blue-grey luminescence.
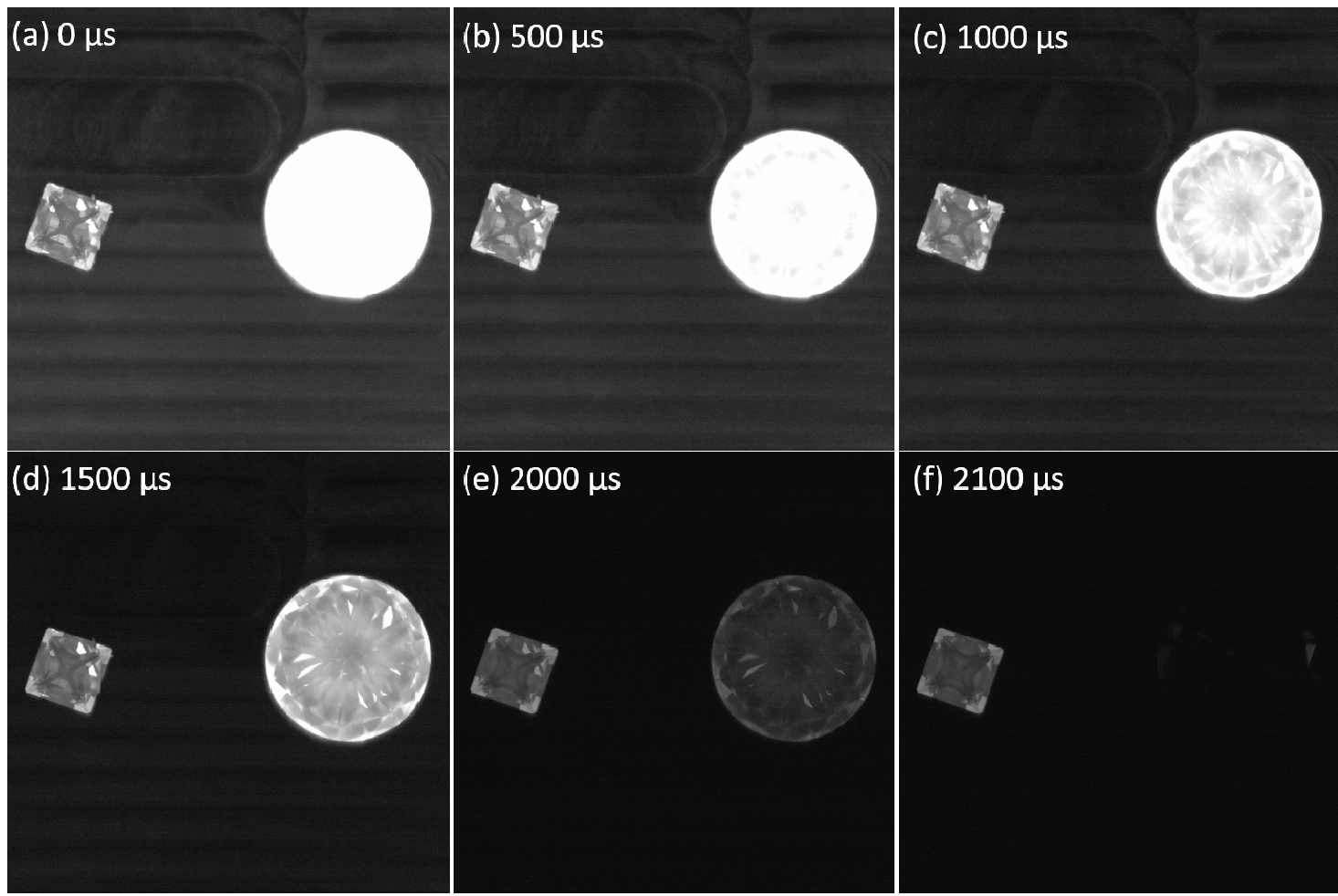

Figure 7. Real-time image capture of same round brilliant diamond (1 ct), as shown in Figure 6 and square-shaped CZ (Princess-cut) of $2.75 \mathrm{~mm}$, as shown in Figure 4a, with increasing exposure delay $(\mu \mathrm{s})(\mathbf{a}-\mathbf{f}), 2 \mathrm{~ms}$ exposure and $2 \mathrm{~ms}$ LED excitation pulse used.

\section{Discussion}

Here, we have shown the application of a novel system based upon time-resolved, near-infrared luminescence imaging, that exploits the observed temporal and spectral characteristics of trace impurities in YSZ. It is believed that there was contribution to the near-infrared emission due to trace $\mathrm{Nd}^{3+}$ and other rare earth elements present in stabilised crystals including YSZ and YAG. Furthermore, the spectral and temporal approach to imaging means that the emission from colour centres present in natural diamond most prominently $\mathrm{NV}^{-}$can be more effectively blocked, thus reducing incorrect 
non-diamond referrals during the (automated) screening of large batches of small diamonds. It is advised, therefore, that any stone with strong infrared delayed emission should be treated with caution, when screening diamond parcels.

The imaging system was constructed from low cost instrumentation, $1 \mathrm{~K}$ Euros in parts: machine vision cameras and relatively skin and eye-safe LED lighting; with all synchronisation carried out by the camera's internal trigger, negating the use of additional complex circuitry.

We believe one of the great advantages of this system is in its potential capability to rapidly screen and therefore differentiate $\mathrm{CZ}$ in jewellery containing very small diamonds $(\leq 0.01 \mathrm{ct})$. In this case, spotting CZ by loupe and SWUV gemmological lamp to observe weak blue-grey luminescence is far more challenging, and more sophisticated conventional means of detection tend to be more expensive, impractical or time consuming to implement.

\section{Concluding Remarks}

In this study, it must be made clear that the colourless $\mathrm{CZ}$ used was arbitrarily purchased from several different suppliers and in many cases, it was not straightforward to obtain information on the melt composition from the producer of the raw material. Of the producers of the raw material that did divulge the stabiliser used, it was invariably $\mathrm{Y}_{2} \mathrm{O}_{3}$, which was verified by $25 \mathrm{kV}$ accelerating voltage and $10 \mathrm{nA}$ probe current EVO50 Scanning Electron Microscopy (Carl Zeiss AG, Jena, Germany) with INCA Energy Dispersive (X-ray) Spectrometer (Oxford instruments, High Wycombe, UK). Therefore, the method described therein will be sensitive to at least YSZ, which is fortunately the main bulk of production of colourless CZ, yielding high quality material well suited for imitation diamond. Furthermore, there is evidence that the strong infrared luminescence also had contribution from trace dopants in the melt i.e., heavy rare earth elements such as $\mathrm{Nd}^{3+}$, as measured from the emission spectrum.

A clear limitation of this method is its inability to screen out all simulants, although this might seem a very significant drawback, the extremely low value of CZ and its optical properties make it make it one the most attractive diamond simulants on the market. As shown in the results from our studies, the method described can be more effective than traditional methods using UV gemmological lamps for detecting CZ, particularly in jewellery with very small diamonds. Therefore, such a technique could be used to complement conventional screening techniques and existing commercial verification instrumentation, perhaps as a quick pre-screen to check for CZ first.

Lastly, in the context of the present-day market, the focus of natural diamond verification instruments is to screen out synthetic diamonds, which is seen as, by far, the largest threat to the industry. Although this is the case, many of the larger jewellery manufacturers still see simulants as a significant threat (again particularly in the small sizes) in their pipeline, as in a lot of cases, CZ is deliberately used in jewellery modelling as a substitute for diamond to test settings etc. CZ has insignificant market value as compared to diamonds, and therefore it is deemed necessary to work in quality control measures, such as those described here into our processes, in order to maintain and sustain a high level of confidence in the industry.

Author Contributions: Conceptualization: P.M.P.L, C.D.M., D.C.J. and S.C.L.; Methodology: P.M.P.L, C.D.M., M.R., C.G.B. and P.A.A.; Software: M.R.; Writing Original Draft Preparation: P.M.P.L. All authors have read and agreed to the published version of the manuscript.

Funding: This research received no external funding.

Acknowledgments: The authors would like to thank H.G. Leach at De Beers Group Technology for mechanical engineering and instrument design effort. Thanks also to B. Boerner at De Beers Diamond Jewellers for construction of the diamond encrusted band used in our investigations. D. C. Jones would like to acknowledge the Diamond Science and Technology Centre for Doctoral Training, University of Warwick, Coventry, CV4 7AL, UK. The authors would also like to acknowledge D. J. F. Evans for his Scanning Electron Microscopy and Energy Dispersive X-ray Spectrometer work.

Conflicts of Interest: The authors declare no conflict of interest. 


\section{References}

1. Nassau, K. Gems Made by Man; Chilton Book Co.: Radnor, PA, USA, 1980.

2. Hall, C. Gemstones. Eyewitness Handbooks; Kyodo Printing Co.: Singapore, 1994.

3. O'Donoghue, M.; Joyner, L. Identification of Gemstones; Butterworth-Heinemann: Oxford, UK, 2003.

4. Pagel-Theisen, V. Diamond Grading ABC: The Manual, 9th ed.; Rubin \& Son n.v.: Antwerp, Belgium, 2001; pp. 298-313.

5. Webster, R.; Read, P.G. (Eds.) Gems: Their Sources, Descriptions and Identification, 5th ed.; Butterworth-Heinemann: Oxford, UK, 2000; pp. 65-71.

6. Boehm, E.W. Portable Instruments and Tips on Practical Gemology in the Field. Gems Gemol. 2002, 38, $14-27$. [CrossRef]

7. De Beers Group Industry Services AMS2. Available online: https:/www.iidgr.com/innovation/automatedmelee-testing2-ams2/ (accessed on 24 September 2020).

8. Swiss Gemmological Institute, Automated Spectral Diamond Inspection (ASDI). Available online: https: //www.ssef.ch/asdi/\# (accessed on 24 September 2020).

9. HRD Antwerp-Equipment, M-Screen 4.0. Available online: https://www.hrdantwerp.com/en/equipment/ detail/m-screen (accessed on 24 September 2020).

10. Dupuy, H.; Phillips, J.C. Selecting a Diamond Verification Instrument Based on the Results of the Assure Program: An Initial Analysis. J. Gemmol. 2019, 36, 606-619. [CrossRef]

11. De Beers Group Industry Services SYNTHdetect. Available online: https://www.debeersgroupservices.com/ en-gb/instruments/synthdetect (accessed on 24 September 2020).

12. Smith, J.; McGuinness, C.D.; Fisher, D. Luminescence Measurements in Diamond. International Patent Application WO/2017/001835, 5 January 2017.

13. McGuinness, C.D.; Wassell, A.M.; Lanigan, P.M.P.; Lynch, S.A. Identification of Natural from Synthetic Diamond using Time-Gated Luminescence imaging. Gems Gemol. 2020, 56, 220-229.

14. Wassell, A.M.; McGuinness, C.D.; Hodges, C.; Lanigan, P.M.P.; Fisher, D.; Martineau, P.M.; Newton, M.E.; Lynch, S.A. Anomalous Green Luminescent Properties in CVD Synthetic Diamonds. Phys. Status Solidi A 2018, 215, 1800292. [CrossRef]

15. Nassau, K. Cubic Zirconia: An Update. Gems Gemol. 1981, 17, 9-19. [CrossRef]

16. Nickel, E.H. The Definition of a Mineral. Can. Mineral. 1995, 33, 689-690.

17. The Gemstone Book; CIBJO/Coloured Stone Commission: Bern, Switzerland, 2018; p. 27.

18. Crowningshield, G.R.; Moses, T. Imitation Crystals. Gems Gemol. 1996, 32, 205.

19. Choudhary, G. Investigating Fake Rough. Gems Jewel. 2018, 28, 26-29.

20. Wentzell, C.Y. Yellow Cubic Zirconia Imitating Cape Diamonds. Gems Gemol. 2005, 41, 340-341.

21. Schefl, H.; Fukuda, T. Crystal Growth Technology; John and Wiley Sons Ltd.: Chichester, UK, 2003; p. 461.

22. Read, P.G. Report on coloured cubic zirconia. J. Gemmol. 1981, 7, 602-605.

23. Gaft, M.; Reisfeld, R.; Panczer, G. Modern Luminescence Spectroscopy of Minerals and Materials, 2nd ed.; Springer Mineralogy; Springer International Publishing: Basel, Switzerland, 2015; pp. 6, 16, 50, 243, 453, 589, 595.

24. Lenz, C.; Talla, D.; Ruschel, K.; Škoda, R.; Götze, J.; Nasdala, L. Factors affecting the Nd3+(REE3+) luminescence of minerals. Miner Petrol. 2013, 107, 415-428. [CrossRef] [PubMed]

25. Assefa, Z.; Haire, R.G.; Raison, P.E. Photoluminescence and Raman studies of $\mathrm{Sm}^{3+}$ and $\mathrm{Nd}^{3+}$ ions in zirconia matrices: Example of energy transfer and host-guest interactions. Spectrochim. Acta Part A 2004, 60, 89-95. [CrossRef]

26. Wang, Q.; Qui, J.B.; Song, Z.G.; Yang, Z.W.; Yin, Z.Y.; Zhou, D.C. Optical properties of $\mathrm{Ce}^{3+}-\mathrm{Nd}^{3+}$ co-doped YAG nanoparticles for visual and near-infrared biological imaging. Spectrochim. Acta Part A Mol. Biomol. Spectrosc. 2015, 149, 898-903. [CrossRef] [PubMed]

(C) 2020 by the authors. Licensee MDPI, Basel, Switzerland. This article is an open access article distributed under the terms and conditions of the Creative Commons Attribution (CC BY) license (http://creativecommons.org/licenses/by/4.0/). 